\title{
Automated Guided Vehicle Routing: Static, Dynamic and Free range
}

\author{
Hameedah Sahib Hasan, MSZ Abidin, MSA Mahmud, M. F. Muhamad Said
}

\begin{abstract}
Nowadays, automated guided vehicles (AGV) play very important role in modern factory automations. The AGV systems provide efficient routing for material flow and distribution among workstations at the exact time and place. Routing of $A G V$ is the process of determining routes to fulfill their respective transport jobs. The routing problem of $A G V$ in production system can be studied as a shortest path problem on a transfer network. It aims to find the shortest path between two vertices or nods. Most transport systems using AGV are centrally controlled and use static routing (pre-defined routes), which follows fixed line. Instead of using fixed path, dynamic routing for $A G V$ can be used to add a high flexibility to the system. To accommodate the increased flexibility and reduced time, new operational controllers using Labview software must be able to adapt to small deviations. In this paper, routing of $A G V$, different AGV shortest path algorithms such as Dijkstra algorithm, A-star algorithm, Short Path Problem with Time Window (SPPTW), hybrid partial swarm optimization and genetic algorithm PSO$G A$ are discussed with highlights of their main differences and comparison between them. AGV Scheduling is presented. In addition, the controller developed within Labview environment directs an $A G V$ in real time using local position system are achieved.
\end{abstract}

Index Terms: Automated Guided Vehicle, AGV Routing, Shortest Path Algorithm, Labview environment, Scheduling, Local Position System

\section{INTRODUCTION}

Automated guided vehicles (AGV) is a vehicle equipped with automatic guidance system, in electromagnetic equipment or optical based system. They are widely used in various fields especially in industrial applications because $\mathrm{AGV}$ is famous as a robot in manufacturing environments (1);(2). The early introduced AGV was in 1950s and its use has increased considerably. It starts from "fetch and carry" to "mobile work station" and finally being used as "intelligent" AGVs with microprocessors controlling various functions. AGV applications have expanded its relevance in industrial environment such as advanced robotics technologies, healthcare, military, and transportation logistics markets (3). The general use for AGVs is basically in transportation of goods in industrial

Revised Manuscript Received on April 19, 2019.

Hameedah Sahib Hasan, Assistant lecturer, Ministry of Higher Education and Scientific Research, Iraq, (Email: hameedah211ou@gmail.com) Mechatronics Engineering, School of Electrical Engineering, Faculty of Engineering, Universiti Teknologi Malaysia Johor Bahru, Malaysia.(Email: shukri@utm.my)

Mohd Saiful Azimi Mahmud, Department of Control and Mechatronics Engineering, School of Electrical Engineering, Faculty of Engineering, Universiti Teknologi Malaysia Johor Bahru, Malaysia.

Mohd Farid Muhamad Said, Associate Professor, School of Mechanical Engineering, Faculty of Engineering, Universiti Teknologi Malaysia (UTM), Johor Bahru, Malaysia.
Mohamad Shukri Zainal Abidin, Department of Control and

warehouses (4). They have different features such as higher flexibility, less weighty and easy execution of assignments. A vehicle can follow prescribed guide path using a vehicle programming and stop selection, and any distinct functions necessary through the system(5). It is generally consisting of two main components, hardware and software. The hardware includes the physical components, like vehicles, path, controllers, sensors etc. The software include algorithms or suitable approaches comparable with hardware resource of the whole AGVS to provide working in the highest efficiency (6); (5);(7).

Most AGVs play an important role in the intelligent material handling system and are widely in flexible manufacturing specially in material handling system that delivers the "right amount of the right materials at the right place, at the right time, in the right sequence, in the right condition, in the right orientation" (8);(9). A material handling system takes the essential position to build and embed an autonomous centralized manufacturing system (ACMS). Recently, free ranging AGV systems are being developed. The vehicles are intelligently designed to route free a given route with high flexibility and speed. The routing flexibility of $\mathrm{AGV}$ makes it useful in many manufacturing systems, especially in purpose of parts with diverse and complex processing routes. Currently, there are many studies on AGV routing to achieve both of high transfer efficiency and reduce labor cost of operations as possible with high productivity (10).

The aim of this paper is to give overview of AGV routing and scheduling. Also, to explain several AGV algorithms used in finding the shortest path such as Dijkstra algorithm A-star algorithm, Short Path Problem with Time Window (SPPTW), hybrid partial swarm optimization and genetic algorithm PSO-GA. Also, the static, dynamic and free-range routing are introduced.

The rest of this paper as fellows: firstly, we present descriptions of AGV routing with explanations on the three types of $\mathrm{AGV}$ routing, fixed routing, dynamic routing and free-range routing, although two of its types are closely associated with each other. Then, we present AGV Algorithms to include several types such as Dijkstra algorithm, A* Algorithm, shortest path problem with time window algorithm SPPTW, Particle Swarm Optimization, Genetic Algorithm and Hybrid PSO-GA Algorithm. Next, we present AGV Scheduling problems. Local Position System is then introduced and finally, AGV Routing Strategies are discussed. 


\section{AUTOMATED GUIDED VEHICLES ROUTINGS}

It can be defined as the ability of $\mathrm{AGV}$ to make decision in guidance path that are able to choose optimum routing (predesign) and exact distention (11). The target of AGV routing is to find route that is shortest with possible time path and also feasible (6). This means routing decision contains several aspects. Firstly, routing should discover if there exists a route that could be leading the AGV from its origin station to the specific destination. Then, the route chosen by AGV motion must be feasible, meaning no congestion, free conflict and no deadlock. Finally, the vehicle route must be an optimal or partially optimal at least, such that, the number of $\mathrm{AGV}$ idleness is minimized (12);(6).

The AGV guidance is taken more important in automation community. The most used types follow the fixed path by using different guidance like magnetic tape, laser, ultrasound sensors, infrared sensors(2);(13);(14);(15). The vehicle follows routes that are fixed into the infrastructure, such as buried wires, painted lines or transponders (16). In static routing or fixed path routing, all the information like position, and cargo demand are identified and route determination cannot change (17). Moreover, real arrival times of the AGVs at their last station are totally random (18). Furthermore, AGVs use a map to follow the routes which are predetermined to travel from first station origin to last station destination (19);(20), i.e. the input data do not change through the path execution (21). This route is recognized between two stations or sites where AGV is moving from site A to site B in fixed path. Static routing is simple, clear and easy to implement. Finally, it is able to immediately, achieve the route computation. On the other hand, it is not suitable with any changes in the environment and transport state. Also, the problems of collision avoidance at execution time and deadlocks affect the system's performance(22);(18). Moreover, the routes are unnecessarily long, meaning the transportation time is high and throughput is low (23). The other type is dynamic routing, proposed to increase the speed of process to finding the AGV routes(24);(12). Normally, it will determine specific routes for each new transportation job (25). Also the routing decision depends on actual-time information for calculating new routes (i.e., the route can change and update during the implementation process (21)). In dynamic routing, for every individual transfer job, the timing and routing can be different. The AGV has the option of choosing a predefined path if feasible, but can dynamically change this path (20) as suitable for the job. Dynamic routing is used to avoid the problems observed in static routing such as collision, deadlock and so on. Also dynamic routing can compute shortest traveling time and conflict-free routes, simultaneously (18). The first name of dynamic routing is incremental route planning introduced by Taghaboni and Tanchoco (1995) to make AGVs comparatively quicker compared with fixed routing. The dynamic programming operations work on the stations to find the best final set that including the optimal results (7). The dynamic routing deals with the routing as a time-space problem and treat to achieving feasible paths in space and time (feasible in the sense of conflict and deadlock free execution of the path)
(26). The last type of AGV routing is free range routing. This route is free-range because it can use of total free space available in the facility without using any fixed paths. This leads to an infinite number of possible routes. Free-range routing provides high alternative to replace other routes type (27). The use of free-ranging adds more flexibility to the system. It increases the efficiency of transportation systems leading to maximizing its throughput(18). It is predicted that the use of a free-range routing process will give a better use of the facility area besides reduced route length compared with fixed path routing system. Moreover, use of free-range information on AGV movements will provide a good flexible deadlock, congestion avoidance mechanisms, and less variation of the planned and realized arrival times (23).

To achieve any of the routing scheme as may be suitable for a given job, several AGV algorithms which are commonly aimed at achieving the shortest feasible paths have been applied in various schemes and are discussed in the next section.

\section{AGV SHORTEST PATH ALGORITHM}

AGV Algorithms focus on finding the feasible routes for AGVs and attempt to provide universal routing solutions for general path (e.g. conflict-free shortest-time path)(6);(7). To find shortest path, several algorithms can be used (28). The design of the algorithm of AGV routing is to make routing optimization easy and feasible as related to arrival time, the avoidance of static obstacles and the planned trajectories of other AGVs. The algorithm of dynamic routing starts with choosing nearest node to visit then next node which is nearest and process is repeated till the last node, representing the destination, is reached (7). The algorithms function based on the status of nearest nodes and the global network details (12). AGV algorithm for dynamic routing is classified to several types (17). The first type of the algorithms is optimal algorithm exactly used to obtain the global optimal solution through the discovery of the total set of available solutions. This type such as the Dijkstra algorithm, represents most common optimal algorithms. Another type is based on heuristic approaches that explore a subset of the available solutions and obtain a near solution this type such as A*. Finally, there is hybrid approach-based algorithms which combines the effects of the strengths of the previous approaches. The best example is Dijkstra with Genetic Algorithm (17).

\section{A. Dijkstra Algorithm}

Dijkstra's algorithm is proposed by a Dutch computer scientist Edsger Dijkstra in 1956 and published in 1959 (29) ;(17). It is used for shortest path problem in graph theory (30). It was commonly utilized to find the navigation cost which is the smallest value by the shortest path planning(31). It is mostly applicable to for use in singlesource shortest path problem. Also, it deals with nonnegative edge path costs for a graph searching. It is used in routing and as a subroutine in other graph algorithms (32). Generally, the shortest path is formed by linking the nodes 
with the lowest values until the end node is reached. It starts from origin (source) node in the graph, then select the linked node and put the value of distance to each node from the start point. After that, the algorithm will check all the nodes in the graph till all the nodes marked with values (30). Dijkstra algorithm has two (2) groups of vertices V and E. Group V include all nodes vertices where the cost is known for the shortest path [v]. On the other side group E includes the unknown value. Once the algorithm begins, group of vertices $\mathrm{V}$ is empty, then one with the vertex having the lowest value move from $\mathrm{E}$ to $\mathrm{V}$. Once a vertex $\mathrm{E}$ is turn to $\mathrm{V}$, the algorithm relaxes check every outgoing edge. The Dijkstra algorithm is very suitable algorithm in most cases but in the same time, it has high computation cost. A computation cycle is time consuming especially when works in a big scale map where the checking action again in $\mathrm{n} 2$ times where $\mathrm{n}$ is the number of nodes on the graph (33) ; (34).

\section{B. A* Star Algorithm}

$\mathbf{A}^{*}$ algorithm is wireless and works in a heuristic-based approached. A* algorithm utilizes the heuristic variable $\mathrm{H}(\mathrm{s})$ and marked it with the current node in the graph search. This will help the algorithm determine if the recent node is a first select for later searching. The algorithm efficiency can be improved by ignoring the irrelevant nodes (30). A* algorithm is generally an extension of the Dijkstra algorithm. However, A*can minimize the complexity of algorithm calculation compared with Dijkstra algorithm (30). Another limitation of the Dijkstra algorithm is that as the number of nodes continues to increase, the efficiency of the Dijkstra algorithm decreases significantly, making the Dijkstra algorithm only applicable to small systems (35). In multi AGV for dynamic path planning, A* algorithm is used to search effectively for both shortest-time path and collision avoidance (22). In graph, $G=\{\mathrm{V}, \mathrm{E}, \mathrm{w}\}$, where $\mathrm{V}$ is the group of nodes, $\mathrm{E}$ is group of edges made by the node connection, w indicates the effective length between two nodes (22).

\section{Short Path Problem with Time Window (SPPTW)}

Shortest Path Planning with Time Windows (SPPTW), basically it means the path which is divided segmented into several parts of fixed period. If there is any conflict, the vehicle will be late in a previous path segment or rerouted. The determination of the paths for the various vehicles is began by a request, containing the nodes at the source and at the destination while the time at entry access (36). To avoid the conflicts, the route timing should be planned instead of at the performance time of route (37);(38).

The determination of the paths for the various vehicles begins by a request, containing the nodes at the source and at the destination during entry access (36). To avoid the conflicts, the route timing should be planned instead of the performance on time of route(37);(38). In addition to the static SPP-algorithm of the time window-based method keeps a list of time periods for each path segment, once the identical edge is not closed by other vehicle. These timeperiods are indicated as time windows. The algorithm will determine the shortest path routing for each request starts from the source node to the destination, dependent on the procedure of its algorithm. Moreover, the SPP algorithm checks within each planning step, if any edge possibly blocks by a last planned path moving to the same edge (36).

The shortest path problem using time window-based algorithm has several advantages in microscopic modeling and simulation of vehicle transference on an airport. Also, it can be used to compute routes like conflict-free, i.e. collisions, deadlocks and livelocks are avoided as shown in Figure 1, when the routes time are planned. But in the a static method, SPPTW avoids complex conflict dealing with the processing of time of the route(36). The main objective of the SPPTW is used to find less cost path between source and the destination regarding the time window condition at every visited node (36).

\section{Particle Swarm Optimization based Routing}

Particle Swarm optimization is a population optimization technique inspired by the social nature of bird flock and fishing school developed by Eberhart and Kennedy in 1995 (40). In PSO, the population term, "swarm" consists of group of particles with each particle moving within search space to find shortest path between the source and the destination (41). The performance of PSO-based routing has several characteristics which is following:

1. Particle Representation: PSO starts with population of particles which represents the solution of problems under study. The particle has its own position $(\mathrm{Pi})$ and original arbitrary velocity (current position and velocity) which is local best $P$ best and global best $P$ best position coverage of the problem space (42). The optimal position is completed when updating the velocity where the position in each iteration must fallow (43).

2. Fitness Function: Fitness function for a particle can determine the initial search function. For each particle transfer within the search area, their velocity will update dynamically depending on equation 1 . Consequently, the position will update through equation 2 . More evaluations are done to update both local and global best only if the current values are better than the previous values. The maximum iteration of this algorithm will generate the global best, which have best fitness $\mathrm{v}_{\mathrm{id}}{ }^{\mathrm{t}+1}$

$$
\begin{aligned}
& v_{i}^{t+1}=w v_{i}^{t}+c 1 r_{1}^{t}\left[p_{i}^{t}-x_{i}^{t}\right]+c 2 r_{2}^{t}\left[p_{g}^{t}-x_{i}^{t}\right] \\
& x_{i}^{t+1}=x_{i}^{t}+v_{i}^{t}
\end{aligned}
$$

The vi, and xi are particle velocity and position vectors respectively and the pi and pg represent the local and global best solutions depending on the last particle position. The weight factor $\mathrm{w}$ explains the dependence of present velocity of particle on its last velocity(43). In traditional PSO, most of the particles have one problem in that the swarm particles have limit they can cover in the total search space and the other problem is they do not rapidly converge towards the current local optimal solution. This is the aim of prematurity and local optimization of PSO. To solve the problem of Prematurity and local optimization, hybrid with PSO is used. 
International conference on Recents Advancements in Engineering and Technology (ICRAET-18) $\mid 15^{\text {th }}{\text { and } 16^{\text {th }}}^{\text {t }}$ March 2019|Siddhartha Institute of Technology \& Sciences, Telangana, India.

\section{E. Genetic Algorithm:}

It was derived from Darwin's theory. It is normally working to supply high goodness of solution for search and optimization problems according to biologically inspired workers like selection, crossover and mutation. Genetic Algorithm (GA) usually begins with an arbitrarily generated set of operators i.e. solutions or chromosomes(39). In every generation, fitness value of every individuals is calculated with fitness function corresponding to the problem. In GA, individuals with high fitness value has more ability to continue in upcoming generation contrast to individuals with low fitness value. In crossover process, two parents exchange their genetic attribute to form a pair of offspring. Basically, the objective of any generation is to obtain higher average fitness value of population than the previous one. GA operators used to determine recent population contains reproduction, crossover, mutation and replacement. Firstly, the reproduction operator describes the probability of reliance of the next population on the solution of recent population. Secondly, the crossover operator chooses couples of solutions named as parents, splits them at arbitrary position by using crossover rate, and swaps their second parts(39). When both reproduction and crossover operators are completed, thirdly mutation operator is used, it chooses an element of a solution using mutation average and swaps with some other elements. In this method, new generations are established which represents the best solutions. Hence, GA introduces a search method, which can be used to generate correct or approximate answers to optimization and search problems.

\section{F. Hybrid PSO-GA Algorithm Based Routing:}

It consists of both PSO and GA algorithm. This PSO-GA algorithm operates in two phases. The First one is suitable for $M$ individuals whose particles are grip when it is being passed for constant value of epochs by algorithm populations. A removing process will be done for the remaining Pop-size $-\mathrm{M}$ individuals. The GA process of selection, crossover, and mutation forms a new Pop-size $\mathrm{M}$ individuals. This is the second algorithm phase. Thirdly, to generate a population for following outcome, the fittest $\mathrm{M}$ individual should max with novel Pop-size-M individuals. This gives the advantage of There will an upraise in the individuals enhancement as time goes by and this is the ultimate goal of PSO-GA study(39).

\section{COMPARISON BETWEEN SHORTEST PATHS ALGORITHM}

Table 1 shows comparison between different algorithm such as Dijkstra algorithm, A* algorithm, shortest path time window SPTW, genetic algorithm GA, Piratical Swarm Optimization PSO and hybrid PSO GA with several parameters including Design complexity, Algorithm Complexity, Map pre-treatment, Speed in large maps, Programming complexity, Accuracy and Adaptability(29). Also, PSO can work in Speed in large maps high and reduce the number of labels saved and dominance computing time. The SPTW can work in in Speed in large maps high where the shortest route from the start to the end node.
Table1. Comparison between Algorithms

\begin{tabular}{|c|c|c|c|c|c|c|}
\hline $\begin{array}{l}\text { Algorithm/ } \\
\text { Features }\end{array}$ & $\begin{array}{l}\text { Dijk } \\
\text { stra }\end{array}$ & $\begin{array}{l}\text { A* } \\
\text { Star }\end{array}$ & $\begin{array}{l}\text { SPP } \\
\text { TW }\end{array}$ & PSO & GA & $\begin{array}{l}\text { Hybri } \\
\text { d } \\
\text { PSO- } \\
\text { GA }\end{array}$ \\
\hline $\begin{array}{l}\text { Design } \\
\text { complexity }\end{array}$ & Low & Low & $\begin{array}{l}\text { Med } \\
\text { ium }\end{array}$ & $\begin{array}{l}\text { Mediu } \\
\mathrm{m}\end{array}$ & $\begin{array}{l}\text { High } \\
\text { qualit } \\
\mathrm{y}\end{array}$ & $\begin{array}{l}\text { Mediu } \\
\mathrm{m}\end{array}$ \\
\hline $\begin{array}{l}\text { Algorithm } \\
\text { Complexity }\end{array}$ & Low & Low & $\begin{array}{l}\text { Med } \\
\text { ium }\end{array}$ & $\begin{array}{l}\text { Mediu } \\
\mathrm{m}\end{array}$ & $\begin{array}{l}\text { Mediu } \\
\mathrm{m}\end{array}$ & $\begin{array}{l}\text { Mediu } \\
\mathrm{m}\end{array}$ \\
\hline $\begin{array}{l}\text { Map pre- } \\
\text { treatment }\end{array}$ & No & $\begin{array}{l}\text { heuris } \\
\text { tic } \\
\text { functi } \\
\text { on }\end{array}$ & No & No & No & No \\
\hline $\begin{array}{l}\text { Speed in } \\
\text { large maps }\end{array}$ & Low & High & $\begin{array}{l}\text { Hig } \\
\mathrm{h}\end{array}$ & $\begin{array}{l}\text { Mediu } \\
\mathrm{m}\end{array}$ & $\begin{array}{l}\text { Mediu } \\
\mathrm{m}\end{array}$ & High \\
\hline $\begin{array}{l}\text { Programmi } \\
\text { ng Compl } \\
\text { exity }\end{array}$ & Low & Low & $\begin{array}{l}\text { Med } \\
\text { ium }\end{array}$ & high & High & High \\
\hline Accuracy & $\begin{array}{l}100 \\
\%\end{array}$ & High & $\begin{array}{l}\text { Hig } \\
\text { h }\end{array}$ & $\begin{array}{l}\text { High< } \\
100 \%\end{array}$ & $\begin{array}{l}\text { High< } \\
100\end{array}$ & High \\
\hline $\begin{array}{l}\text { Adaptabilit } \\
\mathrm{y}\end{array}$ & $\begin{array}{l}\text { Wire } \\
- \\
\text { guid } \\
\text { ed }\end{array}$ & $\begin{array}{l}\text { Wirel } \\
\text { ess- } \\
\text { Guide } \\
\text { d }\end{array}$ & $\mathrm{Ni}$ & $\begin{array}{l}\text { Unive } \\
\text { rsal }\end{array}$ & $\begin{array}{l}\text { Unive } \\
\text { rsal }\end{array}$ & $\begin{array}{l}\text { Unive } \\
\text { rsal }\end{array}$ \\
\hline
\end{tabular}

\section{AGV SCHEDULING}

The scheduling of AGV is used to dispatch a group of AGV to complete set of process such as pickup/drop-off to obtain certain goals (e.g. shortest accomplishment time, least AGV idle time, etc.) in given restrictions (6). In some cases, one classic scenario is to successfully reach all the pickup/drop-off process under the limitations of precedence. Other classic scenario is to improve the scheduling so that the whole travel time of total vehicles is reduced (40), or the number of $\mathrm{AGVs}$ implicated is reduced while the system output is high. According to Le-Ahn (41), the main goal of most scheduling problems is to convey transportation loads (goods, pallets or the containers) as rapidly as possible to suffusion time window constraints. Other parameters such as full load waiting time and higher number of parts in the critical queues can be reduced. Meanwhile, the scheduling are divided into two main factors, a predictive mechanism that calculated the planned start and execution time of labor operations and a interacting mechanism that monitors the progress of the schedule and transact with unpredicted 
actions (cancellations, date changes, breakdowns, etc.) (21). In fact, the scheduling decision might include choosing a vehicle among some idling vehicles or choosing one load between wholly loads to be transported. The problem of choosing a vehicle from a pool of obtainable vehicles constitutes vehicle selection or vehicle-dispatching problem. The corresponding problem of choosing a unit load between those that need transportation is mentioned as a task selection problem (12);(42).

\section{LOCAL POSITIONING SYSTEM (LPS)}

Basically, the Position system has two types that is global positioning system (GPS) and local positioning system (LPS). GPS deals with outside area while LPS deal with inside building to detect location of persons or objects by available local network. Nowadays LPS is used widely in many applications such as $\mathrm{Wi}-\mathrm{Fi}$, radio frequency identification (RFID), ultrasound systems, infrared (IR), Bluetooth, and vision-based systems. LPS used in different technique like TOA,TDOA, RSSI(43). In this paper, the LPS are compared in two section. Firstly, it includes three anchors represented by the receiving part. Second section contains one tag representing the transmitter part as shown as in Figure 1(44). Tag position represented user location in $(\mathrm{x}, \mathrm{y})$ direction. All this LPS component are connected with router which contains all details for those components. In this paper LPS, is used TDOA technique also used UWB related with triangulation method(43);(43). TDOA used when there are at minimum three receivers part and one transmitter part (45);(46);(47).

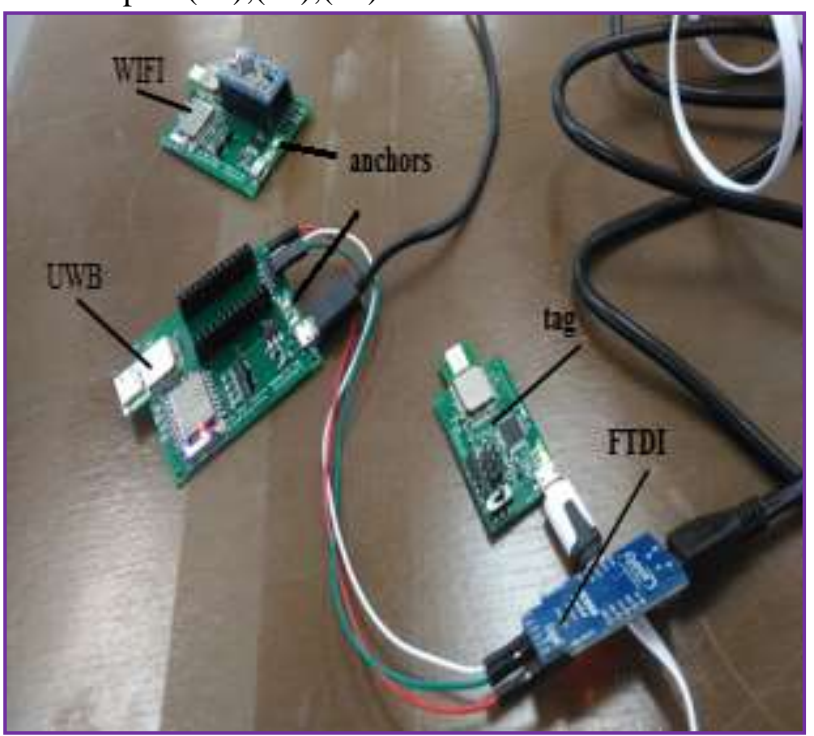

Fig. 1. LPS's Component

In Table 2, we can see the real values and average measured values using 100 samples. Also, the LPS accuracy in $\mathrm{x}$ and $\mathrm{y}$ direction. The maximum accuracy value in $\mathrm{x}$ direction is $16.8 \mathrm{~cm}$ and in $y$ direction $15 \mathrm{~cm}$. Where the minimum accuracy value in $\mathrm{x}$ direction $0.3 \mathrm{~cm}$ and in $\mathrm{y}$ direction $1.2 \mathrm{~cm}$. According to the triangulation method that used in the experiment the best LPS accuracy can be obtained in central of working area that is closed to its real value. This table shows that the LPS accuracy is less than 17 $\mathrm{cm}$ which is a best result in such as work(44).
Table 2 Real values and average measured values

\begin{tabular}{|c|c|c|c|c|c|c|}
\hline \multirow{2}{*}{ No } & \multicolumn{2}{|c|}{$\begin{array}{c}\text { Real values } \\
(\mathrm{cm})\end{array}$} & \multicolumn{2}{c|}{$\begin{array}{c}\text { Average measured } \\
\text { values } \\
(\mathrm{cm})\end{array}$} & \multicolumn{2}{c|}{ Accuracy $(\mathrm{cm})$} \\
\cline { 2 - 7 } & $\mathrm{x}$ & $\mathrm{y}$ & $\mathrm{x}$ & $\mathrm{y}$ & $\mathrm{x}$ & $\mathrm{y}$ \\
\hline 1 & 40 & 80 & 29.3 & 72.4 & 10.7 & 7.6 \\
\hline 2 & 40 & 120 & 45.3 & 110.7 & 5.3 & 9.3 \\
\hline 3 & 40 & 160 & 39.7 & 173 & 0.3 & 13 \\
\hline 4 & 80 & 80 & 68.6 & 75.2 & 11.4 & 4.8 \\
\hline 5 & 80 & 120 & 69.1 & 118.8 & 10.9 & 1.2 \\
\hline 6 & 80 & 160 & 71.7 & 172.7 & 8.3 & 12.7 \\
\hline 7 & 120 & 80 & 116.8 & 67.9 & 3.2 & 12.1 \\
\hline 8 & 120 & 120 & 109.9 & 127.1 & 11.1 & 7.1 \\
\hline 9 & 120 & 160 & 113.8 & 166.7 & 6.2 & 6.7 \\
\hline 10 & 160 & 40 & 152.7 & 38 & 7.3 & 2 \\
\hline 11 & 160 & 80 & 143.2 & 70 & 16.8 & 10 \\
\hline 12 & 160 & 160 & 154 & 175 & 6 & 15 \\
\hline
\end{tabular}

\section{AGV ROUTING}

There are several type of AGV routing scenario. One of them is static routing. It is assumed that the location from start point (origin) and last point (destination), and mapping are fixed (25). In figure 2 shows first type of AGV routing which is called static routing. The AGV move in fixed routing along $\mathrm{x}$ direction as length also fixed routing in $\mathrm{y}$ direction as width.

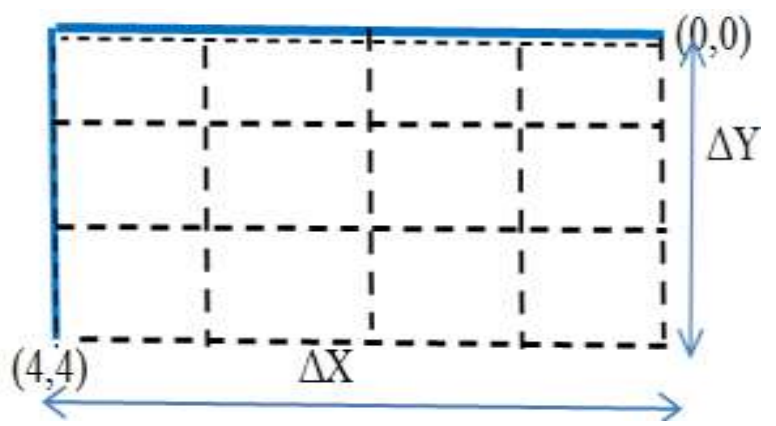

Fig. 2. Static Routing

In figure 3 shows the another type of AGV routing that is called dynamic routing. This routing has own procedure where AGV moved with the shortest route depending on mapping. Both of start point and destination is fixed that is mean fixed paths also are used (20). But the time and route of any individually transportation job are different

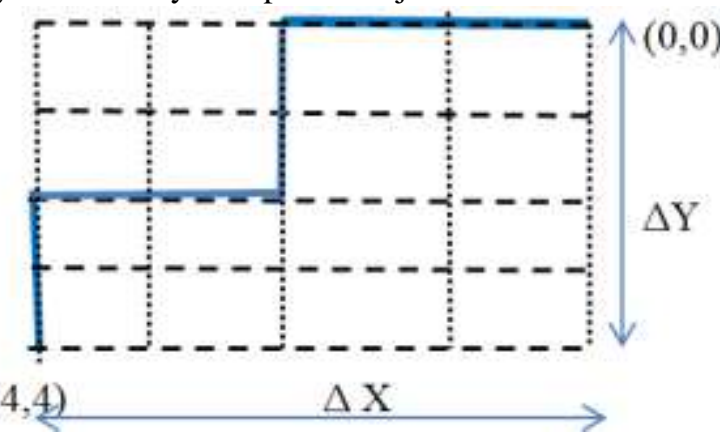

Fig. 3. Dynamic Routing

\section{CONCLUSION}

The AGV routing problem is one of several problems facing $\mathrm{AGV}$ in real time applications. In AGV routing, the AGV should be moved to complete its work within the 
shortest path possible. It aims to finding shortest path between two verticals or nodes. Most transport systems using AGV are centrally controlled and use static routing (pre-defined routes), which follows fixed line. Instead of using fixed path, there is another type such as dynamic routing for AGV can be used to add a high flexibility to the system.. In this paper routing of AGV, different AGV shortest path algorithm such as Dijkstra algorithm, A-star algorithm, Short Path Problem With Time Window (SPPTW), hybrid partial swarm optimization and genetic algorithm PSO-GA, are presented with highlights and several limitations among them are observed. Also AGV Scheduling is presented. Furthermore, the controller developed within Labview environment directs an AGV in real time using local position system are achieved.

\section{ACKNOWLEDGMENT}

The authors are grateful to the Universiti Teknologi Malaysia and the Ministry of Higher Education (MOHE), for their partial financial support through their research funds, Vote No. Q. J130000.2523.19H29.

\section{REFERENCES}

1. MP. G. Automation, production systems and computerintegrated manufacturing. Up Saddle River Pearson. 2008;

2. Han M, Kuo C, Chang NY. Vision-based Range Finder for Automated Guided Vehicle Navigation *. 2016;14651 .

3. M. Han, C. Kuo and NYC. "Vision-based range finder for automated guided vehicle navigation,." 2016;146151.

4. Secchi C, Olmi R, Rocchi F, Fantuzzi C. A dynamic routing strategy for the traffic control of AGVs in automatic warehouses. Proc - IEEE Int Conf Robot Autom. 2015;2015-June(June):3292-7.

5. Hsu WJ. Scheduling and Routing Algorithms for AGVs : a Survey Scheduling and Routing Algorithms for AGVs : a Survey School of Applied Science Nanyang Technological University. 2014;(June).

6. Hsu WJ. Scheduling and Routing Algorithms for AGVs : a Survey. Sch Appl Sci Nanyang Technol Univ. 2014;(June).

7. Qiu L, Hsu W, Huang S. Scheduling and routing algorithms for AGVs : a survey. 2002;745-60.

8. Sen A. A Study of Free Ranging Automated Guided Vehicle Systems. A Thesis Submitt Degree Dr Philos Univ London. 1990;1-185.

9. Bahari A. Automated Guided Vehicles Routing. 2014;1(c):60-6.

10. JEr. Atique Shaikh PAD. AGV Path Planning and Obstacle Avoidance Using Dijkstra's s Algorithm. 2013;2(6):77-83.

11. Jo JD. AGV SYSTEM. 1985;561-2.

12. Taghaboni, F. and Tanchoco JMA. Comparison of Dynamic Routing Techniques for Automated Guided Vehicle Systems. Int'l J Prod Res. 1995;33(10):26532669.

13. L. Schulze and A. Wullner. "The Approach of Automated Guided Vehicle Systems",. IEEE Int Conf Serv Oper Logist Informatics, Shanghai, China,. 2006;522-7.

14. Vis IFA. "Survey of Research in the Design and Control of Automated guided Vehicle Systems." Eur J Oper Res. 2006;170(3):677-709.
15. Medina.C, Segura. J. C. and D la T. "Ultrasound indoor positioning system based on a low-power wireless sensor network providing sub-centimeter accuracy,." Sensors (Switzerland),. 2013;13, n:3501-3526.

16. Ottjes JA, Hogedoorn FPA. Design And Control Of Multi-Agv Systems Reuse Of Simulation Software. 8th Eur Simul Symp Soc Comput Simul Int Genoa, 1996. 1996;

17. Atique Shaikh PAD. AGV Path Planning and Obstacle Avoidance Using Dijkstra' s Algorithm. 2013;2(6):7783.

18. Gawrilow E, Koehler E, Moehring RH, Stenzel B Dynamic Routing of Automated Guided Vehicles in Real-time. Math - Key Technol Futur [Internet]. 2008;165-77. Available from: http://dx.doi.org/10.1007/978-3-540-77203-3_12

19. Duinkerken MB. JAO. A simulation model for automated container terminals. Proc Bus Ind Simul Symp Washingt DC [SCS]. 2000;134-9.

20. Duinkerken MB, Lodewijks G. Routing of AGVs on automated container terminals. Proc 2015 IEEE 19th Int Conf Comput Support Coop Work Des CSCWD 2015. 2015;401-6.

21. Vivaldini KCT, Rocha LF, Becker M, Moreira AP Comprehensive Review of the Dispatching, Scheduling and Routing of AGVs. 2015;505-15.

22. Wang C, Wang L, Qin J. Path Planning of Automated Guided Vehicles Based on Improved A-Star Algorithm *. 2015 IEEE Int Conf Inf Autom. 2015;(August):2071-6.

23. Duinkerken MB, Zee $M$ Van Der, Lodewijks G. Dynamic Free Range Routing for Automated Guided Vehicles. 2006;312-7.

24. Langevin, A., Montreuil, B. and Riopel D. Spine layout design. Int J ofProduction Res. 1994;32:429-42.

25. Duinkerken MB. COMPARISON OF ROUTING STRATEGIES FOR AGV SYSTEMS USING SIMULATION. 2006;1523-30.

26. Smolic-Rocak N, Bogdan S, Kovacic Z, Petrovic T. Time windows based dynamic routing in multi-AGV systems. IEEE Trans Autom Sci Eng. 2010;7(1):151-5.

27. Hao E. A neural network model for the free-ranging AGV route-planning problem", Journal of Intelligent Manufacturing. 1996;7(3):217-27.

28. Saiful M, Mahmud A, Shukri M, Abidin Z, Mohamed Z. Development of an Autonomous Crop Inspection Mobile Robot System. 2015 IEEE Student Conf Res Dev. 2015;105-10.

29. Soyleyici C, Keser SB. Intelligent Systems and Applications in Engineering A Hybrid Algorithm for Automated Guided Vehicle Routing Problem. 2016;169.

30. Dahari M Bin, Yang L. A Review of Auto-GuidedVehicles routing algorithms. 2011;(0):1-17.

31. Saiful M, Mahmud A, Shukri M, Abidin Z, Mohamed Z, Khairie $M$, et al. Multi-objective path planner for an agricultural mobile robot in a virtual greenhouse environment. Comput Electron Agric [Internet]. 2019;157(August 2018):488-99. Available from: https://doi.org/10.1016/j.compag.2019.01.016

32. Shaikh A, Dhale PAD. AGV routing using Dijkstra's Algorithm - A review. 2013;4(7):1665-70.

33. Dijksra EW. A note on two problems in connexion with graphs. NumerMath. 1959;1:269-71.

34. C. Alabas U and BD. , "A self-adaptive local search algorithm for the classical vehicle routing problem,." Expert Syst Appl. 2011;38:8990-8. 
35. Jia F, Ren C, Chen Y, Xu Z. A System Control Strategy of a Conflict-free Multi- AGV Routing based on Improved A * Algorithm. 2017;1-6.

36. Dzikus NN. Dzikus nn. Modelling and simulation of vehicle movements using a spptw-algorithm and the application to airport surface. 2010;

37. Rolf H. Möhring, Ekkehard Köhler E, Gawrilow BS. Conflict-free Real-Time AGV Routing. Oper Res Proc Springer Berlin Heidelberg, 2005. 2004;18-24.

38. Busacker. T. Steigerung der Flughafen- Kapazität durch Modellierung und Optimierung von Flughafen-BodenRollverkehr - Ein Beitrag zu einem künftigen Rollführungssystem (ASMGCS). PhD thesis, Tech Univ Berlin, 2005. 2005;

39. Agnihotri A, Gupta IK. A Hybrid PSO-GA Algorithm For Routing in Wireless Sensor Network. 2018 4th Int Conf Recent Adv Inf Technol. 2018;1-6.

40. Akturk,M. S. and Yilmaz, H. Scheduling of automated guided vehicles in a decision- making hierarchy. Int J Prod Res. 1996;32,:577-59.

41. Le-Ahn T. Intelligent Control of Vehicle-Based Internal Transport Systems. ERIM PhD Ser Res Manag 51 Erasmus Univ Rotterdam. 2005;

42. Egbelu, P. J. and Tanchoco JMA. Characterization of Automatic Guided Vehicle Dispatching Rules. Int'l J Prod Res. 1984;22(3):359-374.

43. Hameedah Sahib Hasan, Mohamed Hussein SMS and MAMD. An Overview of Local Positioning System: Technologies, Techniques and Applications. Int J Eng Technol. 2018;7:1-5.

44. Hameedah Sahib Hasan, Mohamed Hussein, Shaharil Mad Saad and MAMD. Graphical User Interface ( GUI ) for Local Positioning System Based on Labview. Int J Mach Learn Comput. 2019;9(2):236-41.

45. Mannay K, Benhadjyoussef N, Machhout M, Ureña J. Location and Positioning Systems: Performance and Comparison. 2016;16-8.

46. Miši J. An Overview of Wireless Indoor Positioning Systems. 2015;14(March):301-6.

47. Link S-. POSITIONING USING TIME-DIFFERENCE OF ARRIVAL MEASUREMENTS Fredrik Gustafsson and Fredrik Gunnarsson Department of Electrical Engineering. Electr Eng. 2003;8-11.

\section{AUTHORS PROFILE}

Hameedah Sahib Hasan received her B.E., in Mechanical Department from Technology university Bagdad, Iraq; A Master Engineering in Eechanical Engineering, automation and robotics from University College of Engineering, Osmania University, Hyderabad, India, 2013. Currently, She is working towards a doctoral degree from School of Mechanical, Faculty of Engineering, Universiti Teknologi, Malaysia. At present she is working as assistant lecturer, in Ministry of Higher Education and Scientific Research, Al-Furat Al-Awsat Technical University, Iraq.

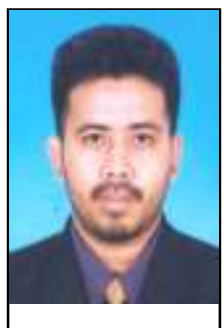

Mohamad Shukri Zainal Abidin received his B. Eng in Electrical Engineering from Universiti Teknologi Malaysia (UTM) in 1998, Msc in Electrical Engineering from Universiti Teknologi Malaysia (UTM) in 2001 and $\mathrm{PhD}$ in Agriculture Engineering from Tokyo University of Technology, Japan in 2014. Currently, he is a Senior Lecturer at Universiti Teknologi Malaysia (UTM) in Control and Mechatronics Department, Faculty of Electrical Engineering and his current research interest involve the adaptive control strategies in fibrous capillary irrigation system and agricultural robotics.

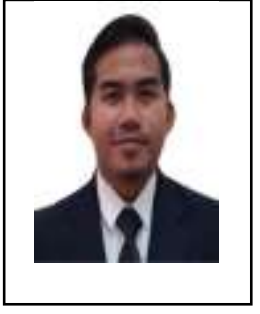

Mohd Saiful Azimi Mahmud received his B. Eng in Electrical Engineering, majored in Control and Mechatronics from Universiti Teknologi Malaysia (UTM) in 2015 and PhD in Electrica Engineering from Universiti Teknologi Malaysia (UTM) in 2019. His research interest is related in the field of multi-objective optimization, robotics and control system and image processing applications.

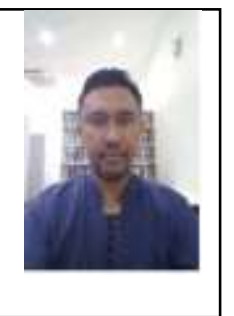

Mohd Farid Muhamad Said completed his PhD degree in 2011 in Mechanical Engineering from University of Leicester, United Kingdom. In 2006, he received his Master (by research) and in 2001 he graduated as a Bachelor in Mechanical Engineering from UTM. His research interests include Internal Combustion Engine, Alternative Fuel and Spray Droplet Characterization and Underwater Vehicle. Currently, he is an Associate Professor at School of Mechanical Engineering, Faculty of Engineering, Universiti Teknologi Malaysia (UTM), Johor Bahru., and he is a member of Society of Automotive Engineering (SAE), Board of Engineer (BEM) Malaysia and American Society of Mechanical Engineers (ASME). 